\title{
LA VIOLENCIA CONTRA LAS MUJERES EN ALBANIA: MEDIDAS PREVENTIVAS ADOPTADAS EN LA LUCHA CONTRA ESTE FENÓMENO
}

\author{
SKERDIAN KURTI \\ Catedrático de Criminología \\ Universidad de Tirana
}

Fecha de recepción: 24.11.2015

Fecha de aceptación: 21.3.2016

\begin{abstract}
Resumen: La violencia contra las mujeres incide sobre su personalidad, su integridad moral y su libertad física, y lo hace a través de acciones específicas y de opresión social. Este tipo de violencia incluye todas las formas a través de las cuales nuestra sociedad convierte a las mujeres en objetos y las reprime. La mujer albanesa siempre ha estado a la sombra del hombre, tanto del padre como del marido. Paulatinamente se han tratado de hacer pequeños cambios, pero lo cierto es que todavia no se ha logrado la igualdad entre el hombre y la mujer. La mujer es estereotipada como "sexo débil" y siempre ha estado subordinada al hombre. Estra realidad es la que más afecta a la violencia doméstica, pues la misma responde a normas culturales y tradicionales. Por esta razón, para prevenir este tipo de violencia en Albania, es preciso analizar las formas en las que se manifesta, sus causas y sus consecuencias.
\end{abstract}

Palabras clave: violencia contra las mujeres, violencia doméstica, estudio de la delincuencia, derecho penal, prevención de la delincuencia

Abstract: Violence against women is a violation of a woman's personality, integrity or mental or physical freedom of movement through specific actions and social oppression. Includes all the ways our society turns women on the subject and press. Albanian woman has always been in the shadow of man, as a father and husband. We have tried to make small changes a little, but not allow a life equal to men is made. Be stereotyped as "weaker sex", women are always subordinate to men. It is always what is 
most affected by domestic violence if they do not respond to cultural norms and traditional mentality. For this reason we must take into account the phenomenon of violence against women in Albania by treating these forms of violence, the causes and factors, consequences and measures to prevent such violence.

Keywords: violence against women, domestic violence offenses, study of crime, criminal law, crime prevention.

SUMARIO: I. INTRODUCCIÓN.- II. LA VIOLENCIA CONTRA LAS MUJERES DESDE UNA PERSPECTIVA HISTÓRICA.- III. FORMAS DE VIOLENCIA CONTRA LAS MUJERES.- 1. La violencia física.- 2. La violencia psicológica.- 3. La violencia sexual.- 4. La violencia económica.- IV. CONSECUENCIAS DE LA VIOLENCIA CONTRA LAS MUJERES: LAS MUJERES COMO VÍCTIMAS.- V. CAUSAS Y FACTORES QUE PROMUEVEN LA VIOLENCIA CONTRA LAS MUJERES.- VI. ACCIONES DEL GOBIERNO CONTRA LA VIOLENCIA DOMÉSTICA Y LA VIOLENCIA CONTRA LA MUJER.- 1. Protección penal y legal contra los actos de violencia sobre las mujeres.- VII. CONCLUSIONES Y RECOMENDACIONES

\section{INTRODUCCIÓN}

La violencia contra las mujeres empieza desde mal uso de la esterilización hasta el abuso de medicamentos con receta expedida, pasando por la pornografía, el acoso y la violación. Incluye el abuso físico y sexual de las niñas y el abuso de los ancianos. Esta forma de violencia, a pesar de que es la violación más generalizada de los derechos humanos en el mundo, sigue estando poco visivilizada. La violencia es también un problema de salud, afecta el bienestar de las mujeres y destruye su dignidad y su autoestima. Es bien sabido que la violencia doméstica cruza todas las fronteras y está presente en todas las culturas.

En un estudio sobre la violencia doméstica realizado por estudiantes de la Facultad de Derecho de la Universidad de Tirana se ha demostrado que el abuso sobre las mujeres es un problema complejo y multidimensional. Los resultados ponen de manifiesto que los factores cultural, social, familiar y personal influyen en las probabilidades de que las mujeres se conviertan en víctimas de este tipo de violencia ${ }^{1}$. En Albania, la violencia doméstica es un problema que afecta negativamente a las mujeres y a los niños, así como a las familias y a las comunidades. Sin embargo, los albaneses tienden a considerar la violencia doméstica como un asunto privado, un

\footnotetext{
1 KURTI, S.: Studim mbi dhunën në familje (La investigación sobre la violencia doméstica), në bashkëpunim me studentët e lëndës Kriminologji dhe Penologji, Departamenti i së Drejtës Penale, Fakulteti i Drejtësisë, Universiteti i Tiranës, maj 2014 (en colaboración con los estudiantes de la asignatura de Criminología y Criminología del Departamento de Derecho Penal de la Facultad de Derecho de la Universidad de Tirana, mayo 2014). Tras la conclusión de este estudio se observó que en la violencia doméstica contra las mujeres existe una combinación de factores psicológicos, sociales y familiares que contribuye a crear una atmósfera que propicia los abusos y que afecta negativamente a la sanción de los autores, debido a la manipulación de las víctimas.
} 
asunto de la familia y como una parte normal de la vida conyugal y familiar. Dado que la violencia doméstica a menudo se produce a puerta cerrada, las víctimas por norma sufren en silencio ${ }^{2}$. La violencia doméstica y la violencia contra las mujeres es un fenómeno generalizado en la sociedad albanesa y, por tanto, es responsabilidad del Estado, de las comunidades y de los individuos adoptar las acciones necesarias para reprimirla. En los últimos años han sido numerosas las iniciativas y las actividades emprendidas por diversas organizaciones para prevenir esta forma de violencia. Por su parte, varios órganos del Estado han contribuído a la unificación y consolidación de estos esfuerzos mediante el fomento y la promoción.

Existe una serie de argumentos que tratan de atraer la atención de la opinión pública respecto de la denuncia y la lucha frete a la violencia doméstica contra la mujer:

- Todos y todas tienen el derecho básico a vivir libremente y sin sufrir violencia alguna;

- La violencia doméstica y la violencia contra las mujeres es una materia pública y no privada, por lo que requiere una especial atención por parte de toda la sociedad;

- La principal causa de la violencia es la desigualdad de poder que existe entre las partes, y es debida a una mentalidad machista;

- Los efectos físicos y psicológicos de la violencia incluyen todas las facetas de la vida. Esto puede llevar en consecuencias como el aislamiento social, el comportamiento antisocial, las dificultades económicas y la difusión de un modelo de relación violenta a los niños;

- Emprender acciones contra la violencia requiere coraje;

- El cambio es un proceso largo, y se enfrenta a una serie de obstáculos y dificultades;

- Exixten distintas formas de violencia, a través de las cuales se busca resolver los conflictos.

El estudio de la violencia doméstica y, por tanto, la lucha contra este fenómeno, se torna más difícil si tenemos en cuenta algunos mitos que no permiten llegar a la esencia del problema. Así, en diferentes comunidades y entornos sociales se comparten las siguentes ideas: la violencia afecta solo a ciertos grupos; la violencia es un problema de los pobres; las mujeres maltratadas tienen una personalidad que desencadena la violencia por parte del cónyuge; las mujeres maltratadas permanecen en relaciones violentas porque la aceptan; la violencia es debida al azar y es muy rara.

La socialización de los hombres y las mujeres en Albania, y el hecho de que se relegue a estas últimas a puestos inferiores, las convierten en sujetos económicamente dependientes y las hace más vulnerables frente a los hombres con los que conviven ${ }^{3}$. La

\footnotetext{
${ }^{2}$ KURTI, S.: Studimi i kriminalitetit nga këndvështrimi i viktimave (El estudio de la delincuencia desde la perspectiva de las víctimas), në bashkëpunim me studentët e lëndës Kriminologji dhe Penologji, Departamenti i së Drejtës Penale, Fakulteti i Drejtësisë, Universiteti i Tiranës, qershor 2012 (en colaboración con los estudiantes de la asignatura de Criminología del Departamento de Derecho Penal de la Facultad de Derecho de la Universidad de Tirana, junio 2012).

3 PEJO, E.: Të drejtat e grave në Evropën e zgjeruar ndërmjet "kulturave të barazisë" dhe sfidave strategjike për të ardhmen (Derechos de las mujeres en la Europa ampliada entre la "cultura de la igualdad" y desafíos estratégicos para el futuro), në Konferencën Shkencore Ndërkombëtare: Mekanizmat e mbrojtjes së të drejtave të individëve në kuadër të proçesit të rregullt ligjor (en la
} 
victimización de las mujeres por parte de sus maridos se ve reforzada por la situación económica, la mentalidad, las tradiciones y la poca conciencia acerca de la violencia doméstica. Las mujeres de todas las culturas sufren violencia, pero más maltratadas resultan las mujeres con bajos ingresos y bajo nivel educativo. Sin embargo, también se detectan casos de violencia sobre mujeres que han tenido accesp a distinto niveles educativos y que se gozan de diferentes estatus socio-económico.

\section{LA VIOLENCIA CONTRA LAS MUJERES DESDE UNA PERSPECTIVA HISTÓRICA}

La sociedad albanesa ha pasado por transiciones y difíciles consecuencias políticas, económicas, sociales y psicológicas, las cuales han dejado su huella, especialmente, a los sectores más vulnerables de la población, las mujeres y los niños. Estudios anteriores sobre la violencia de género en Albania, refuerzan el Canon como una fuente de violencia y maltrato de mujeres albanesas por parte de los hombres, pero no es el único ${ }^{4}$. Históricamente, en el marco del derecho común que ha funcionado durante mucho tiempo en Albania, tuvo una posición subordinada en la familia. Vale la pena mencionar aquí que este derecho tiene el derecho "bashkëekzistuar" oficial del Estado hasta el comienzo de la Segunda Guerra Mundial y en consecuencia con el mismo período ha sido la posición de la mujer en la familia albanesa ${ }^{5}$. Pero a pesar de la influencia de la Canon que selló para siempre el dominio de los hombres sobre las mujeres, las posiciones inferiores de las mujeres también se inscriben como resultado de una continua interacción de muchos factores, cultural, social, plazos, la familia y la persona ${ }^{6}$.

Conferencia Científica Internacional: mecanismos de protección de los derechos individuales en el marco del debido proceso), Pegi, Tirana, 2012, págs. 459 y ss.

${ }^{4}$ El Canon o derecho consuetudinario afecta a la formación de la personalidad del individuo, al dictar la forma de su actuación. Según el Kanun de Lek Dukagjini, Libro Tercero - El matrimonio, el artículo 33: "La mujer tiene el deber de preservar el honor del marido, de permanecer bajo las reglas, para responder a las tareas del matrimonio". Si la mujer no respeta estos principios sancionados por la ley canónica entonces el marido, cuyo comportamiento está basado en el derecho común, reaccionará de la manera especificada en este derecho, es decir, de forma vilolenta contra las mujeres. Sin embargo, a pesar de su posición de subordinación respecto del hombre en la familia, la ley común determina como castigar severamente la violación del honor y la dignidad de la mujer. ÇOBA, L.: Kanuni shqiptar sipas nje doreshkrimi te vitit 1868 (Albanés Kanun según un manuscrito de 1868), en Revistën Drejtësia Popullore (Diario de la Justicia Nacional), n. 5, Tirana, Fakulteti Juridik, Universiteti i Tiranës (Facultad de Derecho, Universidad de Tirana), 1963, pág. 70.

${ }^{5}$ OMARI, L.: E drejta zakonore dhe e drejta zyrtare ne Shqiperi (El derecho consuetudinario y el derecho oficial en Albania), en Revistën Drejtësia Popullore (Diario de la Justicia Nacional), n. 3, Tirana, Fakulteti Juridik, Universiteti i Tiranës (Facultad de Derecho, Universidad de Tirana), 1990, págs. 66-67.

${ }^{6}$ Studim i Qëndrës së Aleancës Gjinore për Zhvillim, Dhuna me bazë gjinore si fenomen shqiptar: Kronologjia e pabarazisë gjinore në Shqipëri-vështrim historik, (Estudio del Centro de la Alianza de Género para el Desarrollo, La violencia de género como fenómeno albanés: Cronología de la desigualdad de género en Albania y reseña histórica), Tirana, 2008. 
El régimen comunista, a pesar del masivo trauma psicológico causado, tuvo un efecto de luz y regeneración para el papel y la condición social y económica de las mujeres en Albania ${ }^{7}$. La mujer no era insignificante en casa, por el contrario, se consideró como un "emancipador" para la sociedad, "igual al hombre" e independiente. El aumento de las demandas de las mujeres a la educación, la inclusión prominente en los ámbitos económico, educativo y social condujo a fortalecer sus posiciones ${ }^{8}$. Sin embargo, este sistema ha dado a las mujeres más libertad fuera de la casa que dentro de ella. Aunque nunca se hizo público, el maltrato a la mujer en la familia y en la sociedad se daba proporciones considerables.

La no igualdad entre el hombre y la mujer ha estado más clara durante la transición económica de los años 1990-1998. El proceso de transición de la planificación centralizada a la economía de mercado ha fortalecido el poder económico de los hombres y perjudicado la independencia económica de la mujer.Como resultado, hubo un aumento significativo en el número de desempleo entre las mujeres, lo que automáticamente también violó su estatus social. Aunque se ofrece un mayor grado de libertad para las mujeres en términos estéticos y cuidados para ellas mismas, la democratización de la sociedad albanesa ha sancionado el inicio de la dependencia económica de la mujer frente al hombre? .

En nuestros días, este fenómeno está considerado por parte de la mayor parte de la población como una cuestión privada de cara a la familia y no la sociedad en su conjunto $^{10}$. A pesar del trabajo de concienciación, especialmente durante los últimos diez años para sensibilizar al público, las actitudes no han cambiado mucho. Sólo un número relativamente pequeño de las mujeres maltratadas en la familia lo denuncian. La única fuente de información sigue siendo en la mayoría de los casos la víctima, que en todo caso no está libre de prejuicios y estereotipos que existen en la sociedad o la comunidad de la que forma parte.

\footnotetext{
${ }^{7}$ Después de la Segunda Guerra Mundial, el papel y la posición de las mujeres albanesas cambiaron, así que en vez de una mujer sumisa, ahora las mujeres albanesas representan a la mujer que está al servicio de "los intereses del país", y ofrecen una gran ayuda en diversos campos de la vida, fortaleciendo así su posición en la familia y la sociedad. HYSI, V.: Politika penale ndaj grupeve të veçanta në shoqëri (La política criminal hacia determinados grupos de la sociedad), en LATIFI, V., ELEZI, I., HYSI, V.: Politika e luftimit të kriminalitetit (La política de lucha contra la delincuencia), Botim i Institutit Evropian për Studime Juridike dhe Administrim Publik, Koha Print, Prishtina, 2012, págs. 172-173.

${ }^{8}$ El Código de la Familia de 1982 ha puesto en evidencia la emancipación de la mujer albanesa de aquellos años. En el artículo 6 del Código establece que "mujer liberada de la opresión económica y política, disfruta de iguales derechos que los hombres".

${ }^{9}$ DHULI, B.: Të drejtat e gruas-mosrespektimi praktik dhe pasojat e tij në ndërtimin e së ardhmes (Derechos de la Mujer desprecio práctica y sus consecuencias en la construcción del futuro), en Revista Studimore-Shkencore, Buletini Shkencor Nr.1 (Revista de Investigación Científica, Nr.1 Boletín Científico), Qëndra kërkimore zhvillimore-Peja, Peja, 2014, pág. 257.

${ }^{10}$ HAARR, R. N.: Dhuna në familje në Shqipëri: Vrojtim kombëtar me bazë popullatën (La violencia doméstica en Albania: la población nacional a base de observación), United Nations Development Program-UNDP, Tirana, 2013, págs. 31 y ss.
} 


\section{FORMAS DE VIOLENCIA CONTRA LAS MUJERES}

Hay varias formas de violencia.Entre las más comunes en Albania, que se enumeran en en base a la experiencia de los centros de servicios para ayudar a las mujeres y niñas violadas, son las siguientes:

- La violencia física,

- La violencia psicológica

- La violencia sexual,

- La violencia económica.

Desde el estudio anterior, realizado por estudiantes de la Facultad de Derecho de la Universidad de Tirana en 2014, muestra que la mayoría de las mujeres entrevistadas conocían y consideraban como actos de violencia todas las formas anteriores y sólo unos pocos conocían la violencia física y la violencia psicológica. Sin embargo, vale la pena mencionar que alrededor del $99 \%$ de las mujeres eran conscientes del hecho de que la violencia contra ellas es punible por el Código Penal ${ }^{11}$.

\section{La violencia física}

\footnotetext{
${ }^{11}$ KURTI, S.: Studim mbi dhunën në familje (La investigación sobre la violencia doméstica), në bashkëpunim me studentët e lëndës Kriminologji dhe Penologji, Departamenti i së Drejtës Penale, Fakulteti i Drejtësisë, Universiteti i Tiranës, maj 2014 (en colaboración con los estudiantes de la asignatura de Criminología del Departamento de Derecho Penal de la Facultad de Derecho de la Universidad de Tirana, mayo 2014): Estudio antes citado. Los resultados de la encuesta señalaron que las mujeres son a menudo propensas a sufrir violencia en el seno de su familia. Cuando se le preguntó la frecuencia de violencia ejercida contra ellas, el porcentaje de respuesta fue elevado (existían, extrañamente, pocos casos en los que las mujeres nunca habían sido maltratadas). Esto evidencia un fenómeno que tiene predisposición a crecer. Así, 4 de cada 5 mujeres respondieron que la violencia estaba latente y 1 de cada 5 mujeres fueron violadas con medios que les habían causado daños. Eran muchos los sujetos que ejercitaban la violencia en la familia, aunque el marido fue el actor principal y dominante. El resultado: es el que la violencia fue ejercida: el $92 \%$ por los cónyuges; $4 \%$ por el $/$ la suegro/suegra; $2 \%$ por el/la cuñado/cuñada; $1 \%$ por los padres; $1 \%$ por los niños.
} 
La violencia física es el uso de la fuerza física en contra de alguien de una manera que duele o que pone en peligro a esa persona ${ }^{12}$. La violencia física incluye una amplia gama de comportamientos tales como rasguños, empujar, obligar mediante la fuerza, picaduras, poner las manos en la garganta, morder, tirar del pelo, doblar el brazo, bofetadas, choques, golpes, patadas, quemaduras, puñaladas, opresión en la garganta o ahogamiento. La violencia física considera el uso del tamaño físico y fuerza, los medios de restricción de la libertad o arma por una persona para ganar y mantener el control sobre otra persona. La violencia física es una forma de violencia que en las víctimas es más fácil de percibir y aceptar por la naturaleza de su ejercicio y huellas visibles que deja en las víctimas.

Las formas de violencia física representa los esfuerzos para controlar y vigilar los movimientos de la mujer. En la mayor parte de los casos, las mujeres que no llevan una vida matrimonial tranquila y no teniendo una relación normal con la pareja,tienen más probabilidad de terminar siendo víctimas de las diferentes formas de violencia física ${ }^{13}$.

\section{La violencia psicológica}

La violencia psicológica ${ }^{14}$ incluye burlas, amenazas, seguimiento post, negando el espacio para tomar decisiones, la prohibición de salir de la empresa o de estar solo, la crítica constante contra la cultura o las costumbres, maldiciendo a la víctima en su casa y en público, cargar de culpa a la víctima por todo lo que sale mal, el control al vestir, etc. La violencia esperitual viene incluida en la violencia psicológica, consistiendo en la prohibición de la liberta de la religión, de las normas culturales y de las tradiciones.

${ }^{12}$ HAARR, R. N., DHAMO, M.: Dhuna në familje në Shqipëri: Sondazh kombëtar me bazë popullatën (La violencia doméstica en Albania: encuesta nacional de base poblacional), INSTAT, Tirana, 2009, pág. 35.

${ }^{13}$ Studim i Qëndrës së Aleancës Gjinore për Zhvillim: Ministria e Punës, Çështjeve Sociale dhe Shanseve të Barabarta (Estudio realizado por Centro de Investigación de la Alianza de Género para el Desarrollo: Ministerio de Trabajo, Asuntos Sociales e Igualdad de Oportunidades), Dhuna në familje: Paraqitje e situatës aktuale (Violencia Doméstica: Resumen de la situación actual), Tirana 2006. En general, esta forma de violencia doméstica se da después del primer año de matrimonio, continúa durante el embarazo, incluso después del nacimiento del primer hijo, y durante toda la vida conyugal si ella no se opone. Los datos muestran que un número considerable de mujeres, víctimas de violencia doméstica, ya la habían sufrido en la familia de origen. Las víctimas indican que sus madres también sufrían violencia por parte de sus maridos y nunca se opusieron. Lo más frustrante es que estas madres desean una vida mejor para sus hijas, pero les han dado el mensaje erróneo, es decir, el mensaje de que "a los hombres se le debe tolerar estos actos".

${ }^{14}$ Botim i Ministrisë së Shëndetësisë (Publicación del Ministerio de Salud), Një qasje praktike ndaj dhunës me bazë gjinore: Udhërrëfyes për punonjësit e shëndetësisë (Un enfoque práctico de la violencia de género: una guía para los trabajadores de la salud), Ribotim, QKSS - Qendra Kombëtare për Studime Sociale, Tirana, 2011, pág. 23. 
Algunas formas de violencia piscológica son:

a) La amenaza de la violencia y las lesiones. La amenaza de los perpetradores de violencia o daño puede ser dirigida contra la víctima u otras personas importantes para la víctima, o pueden ser amenazas de suicidio. A veces la amenaza involucra el asesinato de la víctima, de las personas importantes para la víctima e incluso del propio agresor. Las amenazas se pueden hacer directamente con las palabras (por ejemplo, "Voy a matarte", "Tu eres mía", "Por esto pagará tu madre", "No puedo vivir sin ti"), o por acción (por ejemplo, mostrar las armas, secuestros, intento de suicidio). Los perpetradores pueden ser violentos hacia los demás (vecinos, familiares, hijos, etc.) como una herramienta para aterrorizar a las víctimas. Los hackers pueden obligar a las víctimas a hacer algo ilegal (prostitución, el robo) y luego amenazar con mostrar públicamente lo que han hecho, o pueden hacer falsas acusaciones en su contra.

b) Los ataques contra la propiedad, o los animales domésticos y otros actos de intimidación. Los ataques contra la propiedad y las mascotas no son casos raros ( la víctima esta al lado de la pared y el hombre que avisa golpea la pared con un martillo, o por el contrario ella está detrás de una puerta cerrada que él golpea; coge el perro o el gato de la víctima y le pega;rompe los objetos que están encima de la mesa diciéndole" mira lo que me has obligado a hacer "). El mensaje es siempre la víctima, "la próxima vez te toca a ti". Los miedos pueden realizarse sin daño a la propiedad, jurar, gritándole a la cara de la víctima, conducir el coche a mucha velocidad cuando al lado están la mujer y los hijos,etc. El abuso verbal, aunque no es físicamente dañino y no tiene signos visibles, es muy perjudicial. En realidad, los casos de abuso psicológico incluso cuando son graves, los ataques constantes pueden ser muy perjudiciales para su salud, incluso peor que el abuso físico, u otras formas abuso.

\section{La violencia sexual}

La violencia sexual ${ }^{15}$ incluye sexo forzado, tratamiento de la pareja como un objeto sexual, la obligación de tener relaciones sexuales sin consentimiento de la pareja, la obliga a practicar sexo en las formas que a él le gustan, la determinación de tocar y de hacer lo que quiere el hombre, la obligación de tener relaciones sexuales con otra pareja o con el propio cónyuge/pareja, la realización de sexo con otra pareja a los ojos de su esposa, obligar a la mujer a practicar sexo después de haber usado la violencia física, tener que ejercer la prostitución, tener que hacer un striptease, etc. De acuerdo con los estudiosos, la violencia sexual, se divide en cuatro categorías:

\footnotetext{
${ }^{15}$ Estudio realizado por United Nations Development Program-UNDP, Dhuna në familje: Përgjegjësitë që ka Policia e Shtetit për parandalimin dhe reduktimin e saj (Violencia doméstica: Responsabilidades de la Policía del Estado para prevenir y reducir), Tirana, 2008. Sobre la base del centro de asesoramiento de datos, ésta es la tercera forma de violencia que se ejerce sobre las mujeres. En este caso hay que destacar que a pesar de que la violencia sexual puede ser el tercero en cuanto a su frecuencia, está cada vez más presente y se combina con otras formas de violencia, la violencia psicológica y física.
} 
a) uso de la fuerza física para tener relaciones sexuales sin consentimiento de la mujer, aún cuando el acto no se completa, entonces no se realiza la relación;

b) intentar tener relaciones sexuales con una mujer que no está consciente y es incapaz de comprender o oponerse al acto sexual (estar borracha, enferma, drogada, incapaz, o está bajo presión).

c) contacto sexual abusivo, incluyendo el tocar los genitales o partes del cuerpo sin su deseo o consentimiento por razones de condición física o mental (estar enferma, drogada, borracha o está bajo presión).

d) negación del uso de anticonceptivos, o la protección contra las enfermedades de transmisión sexual. A menudo, en estos casos, el mesaje del perpretador de la víctima es que no son dueños de su cuerpo.

\section{La violencia económica}

La violencia económica tiene que ver con el control de las mujeres sobre los ingresos, la familia o incluso prohibir la participación de las mujeres en las decisiones sobre el gasto de dinero, incluso la negativa de dar dinero para cubrir las necesidades básicas del hogar, denegación de propiedad sobre la propiedad conjunta, daño o destrucción de la propiedad, el robo de la propiedad, obligar a la mujer con el objetivo de robar o por el contrario vender bienes de valor, mantener oculto el dinero, retener en casa sin opción a trabajar ${ }^{16}$.

\section{CONSECUENCIAS DE LA VIOLENCIA CONTRA LAS MUJERES: LAS MUJERES COMO VÍCTIMAS}

Como resultado del ejercicio de las diversas formas de violencia contra la mujer tiene como consecuencia problemas graves de salud ${ }^{17}$. Estas consecuencias se pueden resumir en tres grupos:

a) Consecuencias asociadas con la salud mental, depresión, miedo, ansiedad, falta de autoestima, anorexia e insomnio, trastornos postraumáticos, intento de suicidio.

\footnotetext{
${ }^{16}$ Estudio de la Organización para la Seguridad y la Cooperación en Europa-OSCE, Manual: Si të kërkojmë mbrojtje nga dhuna në familje (Manual: Cómo buscar la protección contra la violencia doméstica), Tirana, 2013.

${ }^{17}$ SHEHU, E., GRAMO, A.: Dhuna me bazë gjinore: Manual për punonjësit e shëndetësisë (Violencia de género: Un Manual para trabajadores de la salud), Tirana, 2008, pág.16.
} 
b) Consecuencias asociadas con la salud física: muerte, incapacidad física o parcial permanente, lesiones, abuso de drogas y alcohol, síndrome de intestino irritable, el tabaquismo o practicar sexo sin preservativo.

c) Consecuencias relacionadas con la salud reproductiva, los embarazos no deseados, problemas ginecológicos, enfermedades de transmisión sexual, abortos, bajo peso al nacer, etc.

Las consecuencias para la salud de la violencia contra la mujer son enormes, incluyendo no sólo a las mujeres sino también a los niños víctimas de abusos o de otros miembros de la familia y la comunidad en general. Algunas mujeres maltratadas comienzan a sufrir problemas de salud mental y se vuelven dependientes de otros miembros de la familia que agravan aún más la situación.

Los estudios han demostrado que las mujeres maltratadas reaccionan de diferentes maneras a la violencia perpetrada en su contra. La mayoría de ellas reaccionan culpándose a sí mismas por la violencia en el hogar. Ellas siempre creen que podrían haber evitado perjudicar a su pareja. Tienen una gran cantidad de estrés al tratar de controlar su comportamiento y para satisfacer sus maridos ${ }^{18}$. Otro grupo de mujeres maltratadas se sientn desesperadas, porque piensan que la violencia doméstica es parte de la vida conyugal. Han visto el mismo modelo con sus madres y abuelas. Así, lo toman como parte de sus vidas ${ }^{19}$. El tercer grupo de mujeres maltratadas comienzan a subestimarse a sí mismas y sienten que no son adecuadas para sus parejas, ellas creen que no tienen valores, que no valen nada o no son capaces de hacer cualquier cosa, y se ponen en situación de dependencia ${ }^{20}$. Otras mujeres reaccionan al quejarse por el comportamiento de sus maridos, primero entre la familia y luego, en caso de repetirse, buscan especialistas de soporte. Otras mujeres estan lejos de casa y buscan refugio con familiares o en centros de acogida para las mujeres. En cualquier caso, cada mujer maltratada encuentra su manera de responder a la violencia, que depende del nivel de conciencia, educación, capacidad de luchar en defensa de sí misma, el apoyo recibido de la familia de origen, situación económica, el apoyo de los niños y la información que tiene sobre los servicios sociales existentes.

\footnotetext{
${ }^{18}$ BABAN, A.: Dhuna ndaj grave në familje në Shqipëri (La violencia contra las mujeres en Albania), Unicef, Tirana, pág. 9.

${ }^{19}$ KOSTA, A.: Dhuna në familje dhe ndaj grave (La violencia doméstica y hacia las mujeres), Tirana, 2007, pág. 2. El pequeño número de denuncias de mujeres maltratadas muestra que la violencia contra las mujeres se considera como un asunto privado, que se oculta a la opinión pública y a la policía.

${ }^{20}$ Además de las consecuencias anteriores, una de las mayores consecuencias de la violencia doméstica es todo el daño que causa la violencia extrema. Después de las lesiones, las víctimas se enfrentan a numerosos problemas psicológicos, a la incapacidad para cuidar de los hijos, a ideas e intentos de suicidio, a la interrupción de la formación y, por tanto, no pueden trabajar, lo que no influye a su vez en su situación económica. LUARASI, I., FUGA, A., PILIKA, A., GADESHI, E.: Studim për viktimat e krimit të dhunës në familje dhe sulmeve seksuale (Estudio sobre las víctimas de delitos de violencia doméstica y asalto sexual), Edlora, Tirana, 2013, pág. 67.
} 


\section{CAUSAS Y FACTORES QUE PROMUEVEN LA VIOLENCIA CONTRA LAS MUJERES}

Ninguna de las formas de violencia contra la mujer debe de ser tolerada, pero para tener una lucha eficaz contra este fenómeno es importante entender las causas que fomentan y permiten tal cosa. Las causas de la violencia contra las mujeres en Albania tienen diferentes génesis y en gran medida se pueden agrupar en cinco grupos.

- Las causas individuales: relacionados con las características de personalidad y problemas, como los celos y la dependencia emocional, la inmadurez, la falta de control, sentimientos de inferioridad, falta de inteligencia;

- El ambiente y la educación familiar: un alto porcentaje de los hombres que han sido abusados físicamente o han sido testigos de la violencia doméstica se convierten en víctimas. Estas primeras experiencias han influenciado y provocado en estos hombres ira interna, baja autoestima y una manera de resolver la ira violentamente. Mientras tanto, en las zonas rurales sigue siendo preservar el típico modelo de familia patriarcal, donde conviven varias personas y algunas parejas en la misma casa, lo que favorece al maltrato en detrimento de la mujer ${ }^{21}$. Por el contrario podemos destacar aqui, los modelos de un buen comportamiento de los padres, el elevado número de hijos, la convivencia en familia con muchas mujeres, el control de la vida conyugal, limitación de las posibilidades de una vida mejor;

- Las causas sociales: entre las causas sociales podemos mencionar cómo la sociedad percibe la violencia en general, y como se refleja en los medios de comunicación, la pobreza y el desempleo, los altos niveles de estrés, disminución significativa del nivel de la educación, la pérdida de confianza en las instituciones del Estado, política y la inestabilidad económica, el aislamiento social, la traición, el abuso de drogas y alcohol, la adicción a los juegos de azar);

- La inconsistencia de las ideologías entre generaciones: en las zonas rurales ha habido pocos casos de violencia que han degradado a los delitos contra la vida

\footnotetext{
${ }^{21}$ XHAFERI, A.: Shkaqe dhe faktorë që nxisin dhunën ndaj gruas (Causas y factores que promueven la violencia contra las mujeres), në Konferencën shkencore ndërkombëtare: Demokracia në Evropën Juglindore (en Conferencia Científica Internacional: La democracia en Europa del Sud-Este), Vëllimi 1 (Volumen 1), Tetova, 2014, págs. 7 y ss.
} 
cometidos principalmente contra las niñas "con una mala educación" por los padres debido a la violación del honor de este último. Así, por un lado se encuentra la generación de más edad criado y educado por una mentalidad no contemporánea y por otra parte la más joven que se está adaptando al desarrollo de la sociedad moderna.

- La prevalencia del derecho consuetudinario: las causas que afectan al uso de la violencia contra la mujer son de lo más variado, pero en términos de la realidad albanesa, este fenómeno se ve favorecido en gran medida por la función patriarcal de la sociedad y la prevalencia del derecho consuetudinario ${ }^{22}$. Aplicabilidad de los valores de Kanun y culturales que toleran comportamientos violentos contra las mujeres va en la misma dirección que y mentalidad de los países balcánicos que conduce a una falta de respeto hacia las mujeres.

\section{ACCIONES DEL GOBIERNO PARA ADAPTAR EL SISTEMA EN FUNCIÓN DE LA GUERRA CONTRA LA VIOLENCIA DOMÉSTICA Y VIOLENCIA CONTRA LA MUJER}

Para combatir, pero sobre todo para prevenir, la violencia contra las mujeres se están tomando una serie de medidas, ya sean de carácter legislativo o de carácter social.

Durante estos años, Albania ha adoptado una serie de actos internacionales que establecen el estándar, para las medidas que los Estados deben tomar para prevenir y combatir la violencia doméstica. Vale la pena mencionar aquí, el Convenio del Consejo de Europa de "En la prevención y la lucha contra la violencia contra las mujeres y la violencia doméstica", que constituye el primer documento internacional con fuerza legal que establece amplias medidas para prevenir y combatir la violencia contra las mujeres y la violencia en la familia ${ }^{23}$.

\footnotetext{
${ }^{22}$ KURTI, S.: Analiza e shkaqeve të dhunës në familje dhe reagimi i jurisprudencës përballë rasteve të tilla (Análisis de las causas de la violencia doméstica y la jurisprudencia reacción opuestos tales casos), në Konferenën Shkencore Ndërkombëtare: Shteti, shoqëria, e drejta - shqiptarët 25 vjet nga ndryshimi i sistemeve (Internacional Científico Conferencia: Estado, la sociedad, a la derecha - albaneses de 25 años de sistemas de cambio), Universidad "Alexander Moisiu", Durres, mayo 2015. Perspectivas de la sociedad sobre el papel de la mujer en la familia, que se define como uno de los principales factores que afectan a la creación de situaciones familiares violentas. El abuso psicológico y físico a menudo se presenta como resultado de la oposición o rebelión contra los roles y expectativas de género existentes. La mentalidad patriarcal de la familia albanesa es vista como un factor que afecta a la violencia en la familia de origen y en la nueva familia.

${ }^{23}$ Convenio del Consejo de Europa, de fecha 11.05.2011, conocido como el Convenio de Estambul, en el artículo 3, define la violencia contra las mujeres: "la violencia contra la mujer se entiende como una violación de los derechos humanos y una forma de discriminación contra la mujer y se entenderá a todos los actos de violencia de género que conducen o pueden conducir a lesiones o física, sexual, psicológica o económica a las mujeres, incluidas las amenazas de rendimiento de tales actos, la coacción o la privación arbitraria de la libertad, tanto si se producen en la vida pública o privada".
} 
Antes de la ratificación del Convenio de Estambul, el legislador ha aprobado la Ley Nr. 9669, de fecha 18.12.2006, "Sobre las medidas contra la violencia doméstica", que tiene por objeto prevenir y limitar la violencia en todas sus formas ${ }^{24}$.

Las modificaciones del Código Penal de 2012 y 2013 han dado un paso significativo en la lucha contra la violencia doméstica en general y la protección de las mujeres en particular. Antes de estos cambios, la legislación penal albanesa no prevé ninguna disposición específica para castigar la violencia doméstica, que mantiene en general una cantidad muy baja de delincuencia cotidiana de la violencia contra las mujeres ${ }^{25}$.

La estrategia de la Policía del Estado durante 7 años (2007-2013) se ha fijado como prioridad "reducir aún más la delincuencia y comportamiento antisocial". En este contexto, se presta especial atención a la reducción de la violencia doméstica a través de medidas legales y la formación continua del personal de policía, que se enfrentan a este tipo de casos.

De acuerdo con la Ley Nr. 9669, de fecha 18.12.2006, "Sobre las medidas contra la violencia doméstica", el Ministerio del Interior y la Dirección General de la Policía han emitido diversos actos legales, pedidos y documentos para garantizar la aplicación de la ley, de la siguiente manera: Nr. de pedido 379, de fecha 03.03.2008 del Ministro del Interior "Sobre las medidas para la prevención y reducción de la violencia doméstica y el tratamiento de las víctimas de la violencia doméstica"; Nr. de pedido 981, de fecha 31.10.2008, del Director General de la Policía "Sobre las medidas que deberá adoptar la Policía del Estado para prevenir y reducir la violencia doméstica, el tratamiento de las víctimas de la violencia doméstica"; Desde 2008, se aplica Manual "En los procedimientos estándar para ejecutar el agente de la Policía del Estado sobre las medidas para prevenir la violencia, proteger y cuidar a las víctimas de la violencia doméstica", aprobado por la Orden Nr. 1035, de fecha 17.11.2008 por el Director General de la Policía; Nr. de pedido 344, de fecha 05.10.2010 del Ministro del Interior "Sobre las enmiendas a la orden del Ministro del Interior Nr. 251, de fecha 15.02.2008, para la elaboración de estadísticas sobre la delincuencia" ${ }^{26}$.

Decisión del Consejo de Ministros Nr. 505 de fecha 13.07.2011 "Sobre la aprobación de las normas de los servicios sociales de atención a víctimas de violencia doméstica, en residencial, público y no público", así como la correspondiente

24 Ley Nr. 9669, de fecha 18.12.2006, "Sobre las medidas contra la violencia doméstica", Stimortunidades. Otras autoridades responsables son: Ministerio del Interior, Ministerio de Salud, Ministerio de Justicia, Ministerio de Educación y Ciencia, unidades de gobierno locales, autoridades judiciales (tribunales). Responsabilidades de los Tribunales bajo la Ley "Sobre la violencia doméstica" en relación con el examen de las solicitudes para la emisión de las órdenes de protección. Entre otras cosas, esta ley establece las medidas legales pertinentes para la protección de los miembros de la familia que son víctimas de violencia doméstica, prestando especial atención a los niños, los ancianos y las personas con discapacidad.

${ }^{25}$ Botim i OSCE, Analiza e sistemit të drejtësisë penale në Shqipëri: Raport i programit për zhvillimin e një gjykimi të drejtë (Publicación de la OSCE, Análisis del sistema de justicia penal en Albania: Informe del programa para el desarrollo de un juicio justo), OSCE, Tirana, 2006, págs. 120-123.

${ }^{26}$ Este pedido confirma: a) la creación de registros separados para la grabación de los casos de violencia doméstica, que son administrados por cada Director Regional de Policía; b) la creación de formularios estadísticos para registrar los casos de violencia doméstica y c) la creación de estructuras especiales de la policía para identificar, gestionar y completar los registros y formularios estadísticos, creado en cada Director Regional de Policía. 
Instrucción Nr. 13, de fechas 12.17.2012 "en la aplicación de las normas de los servicios de atención social a las víctimas de la violencia doméstica, en residencial, pública y privada". Normas destinadas a mejorar las vidas de las víctimas de violencia doméstica y sus familias. Ellos reflejan las mejores prácticas en este ámbito y los principios internacionales de igualdad, el respeto y garantía de los valores y la personalidad de la persona, el derecho a beneficiarse y proteger, la protección de la información acerca de los dignidad y seguridad, la asociación, la integración social y la participación en la vida comunitaria. Este documento consta de siete normas básicas. Además de las normas, tiene en cuenta los criterios de evaluación, indicadores de medición de la calidad del servicio y los resultados guía. Las normas tienen por objeto: a) normas básicas de servicio; b) norma obligatoria para todos los que prestan servicios públicos y privados. Las normas son un requisito previo para la prestación del servicio, el proceso de concesión de licencias, inspección y evaluación de los servicios sociales, que son ofrecidos por entidades públicas y privadas. Implementación del paquete estándar de servicios para esta categoría que garantiza la prestación de un servicio de calidad a las víctimas de la violencia doméstica ${ }^{27}$.

El Gobierno de Albania, con el apoyo de varias organizaciones internacionales y las organizaciones sin fines de lucro, ha desarrollado varias estrategias que se pueden aplicar y se encuentran en la prevención de la violencia doméstica: a) La estrategia nacional y plan de acción para la igualdad de género y la violencia doméstica, que establece las políticas y acciones de las estructuras, incluyendo también a los órganos de la policía para prevenir y responder a la violencia doméstica); b) Estrategia de Servicios Sociales, 2005-2010, del Ministerio de Trabajo, Asuntos Sociales e Igualdad de Oportunidades - Departamento de Servicios Sociales. Este documento fue aprobado por el Consejo de Ministros, Nr. 265, de fecha 28.4.2005. Dentro de esta estrategia se identifican los principales grupos de personas que necesitan apoyo y servicios sociales. Uno de ellos son mujeres, además de otros grupos involucrados como mujeres maltratadas y las mujeres divorciadas; c) La estrategia nacional para el desarrollo social y económico. Esta estrategia tiene como objetivo implementar políticas de mitigación social de la pobreza. Se hace hincapié en la prestación de servicios específicos que se ofrecen a los grupos vulnerables de la población (niños, jóvenes, mujeres, ancianos) para responder a sus necesidades. La estrategia no menciona específicamente la violencia doméstica y no proporciona las políticas de protección, pero cumple con su prevención; d) Estrategia para el empleo y la formación profesional. El marco de esta estrategia proporciona programas de extensión para mujeres desempleadas con profundos problemas sociales, que sirve a la prevención de nuevos actos de violencia en la familia; e) Estrategia nacional de lucha contra la trata de seres humanos: el marco y plan de acción estratégico nacional, 2005-2007. En base al marco estratégico, la violencia en familia está considerada como motivo de tráfico de personas. El apoyo de los diversos programas del gobierno para la educación, los medios de comunicación y otros medios de información a la comunidad, especialmente las mujeres, los niños y los grupos desfavorecidos sobre la trata, constituyen un objetivo específico de este marco estratégico; Estrategia y Plan de Acción "sobre la policía estatal para el período 2007-2013", que define las metas y objetivos que debe alcanzar

\footnotetext{
${ }^{27}$ HAXHIYMERI, E., KULLURI, E., POST, D.: Standardet e shërbimeve të përkujdesjes shoqërore për viktimat e dhunës në familje, në qendrat rezidenciale, publike dhe jopublike (Normas de servicios de asistencia social para las víctimas de la violencia doméstica, en residencial, público y privado), UNDPProgrami i Kombeve të Bashkuara për Zhvillimin (Programa de Naciones Unidas para el Desarrollo), Tirana, 2013, pág. 8 .
} 
la Policía del Estado durante los seminarios con la población en algunos barrios y en la prevención y eliminación de la actividad criminal.. También está previsto la creación de las nuevas estructuras que se ocuparán de la prevención y trato de los casos de violencia en familia y con la tutela de menores.

Un número considerable de organizaciones sin fines de lucro están tratando de abordar el problema y proponer diversas medidas para su prevención. Al mismo tiempo, las organizaciones de mujeres participan cada vez más en el movimiento para la protección de los derechos de las mujeres, la organización de campañas de sensibilización pública sobre este tema y proporcionan servicios y apoyo a las mujeres, niñas y niños maltratados.

\section{Protección penal y legal contra los actos de violencia contra las mujeres}

En 2012 y 2013, el Código Penal de la República de Albania sufrió cambios en la parte general y su parte especial en términos de protección de las mujeres de diversas formas de delincuencia, incluida la violencia doméstica. Los cambios en la parte especial del Código Penal trajeron el aumento de los delitos, los cambios o correcciones a las regulaciones existentes. Algunos cambios fueron dictados por el crecimiento de la delincuencia, otros respondían a la necesidad de ajustar la legislación albanesa a las normas internacionales.

2012 y 2013 se caraterizaron por la criminalización de las formas de la violencia doméstica, el aumento de la sensibilidad de las víctimas a denunciarlo y el aumento de denuncias registradas de violencia doméstica

Por primera vez, añadió al Código Penal, artículo 130/a, titulado "Violencia Doméstica" $^{28}$. A través de este artículo, el legislador da la definición de lo que se llamará la violencia, proporcionando sanciones adecuadas para cualquier ocasión. Este artículo proporciona tres niveles de violencia doméstica:

- Paliza, así como cualquier acto de violencia perpetrados por personas en las relaciones familiares que violan la integridad física, el desarrollo psico-social y económica de las víctimas ${ }^{29}$.

- Amenaza grave para causar la muerte o lesiones graves infligidas por personas en las relaciones familiares resultantes de violación de la integridad psicológica de la víctima ${ }^{30}$.

\footnotetext{
${ }^{28}$ Este artículo se refleja en la parte especial del Código Penal, Capítulo II titulado : "Delitos contra la persona: Delitos contra la vida", la Sección IX, titulado "Delitos contra los niños, el matrimonio y la familia".

${ }^{29}$ En el Parlamento hubo animadas discusiones en relación con las acciones u omisiones que debían de ser castigadas por este crimen. Teniendo en cuenta que las formas de violencia física son diferentes y que no puede haber una lista exhaustiva de todas, el legislador decidió establecer el contenido del artículo 130/a del Código Penal, que castiga toda forma de violencia. En este caso se trata de un delito punible con hasta dos años de prisión. HYSI, V.: Politika penale për veprat penale kundër grave dhe fëmijëve (Política criminal en relación a los delitos contra las mujeres y los niños), në Revistën "Studime Juridike" Nr.2, Fakulteti i Drejtësisë, Universiteti i Tiranës (en Revista "Estudios Jurídicos" Nr.2, Facultad de Derecho, Universidad de Tirana), Europrint, Vlora, 2014, pág. 51.

${ }^{30}$ Inicialmente, el Código Penal en el artículo 84 estipulaba el delito de lesiones mortales y graves sin hacer distinción por motivos de amenaza. Durante el período 2001-2012 se incluye hasta cuatro veces en el Código Penal, mediante la introducción de delitos específicos como, la amenaza para la venganza o la vengaza de sangre, la amenaza por motivos de racismo y la xenofobia, a través de un sistema informático.
} 
- Hiriendo, se cometen intencionalmente perpetrado por personas en las relaciones familiares que causaron incapacidad temporal para trabajar más de nueve días ${ }^{31}$.

En 2012 añadió al Código Penal, artículo 121/a, titulado "Persecución" y que está destinado a proteger a la mujer de los que tratan de provocar un estado de ansiedad o temor constante y grave para la seguridad personal, o para forzar el cambio su manera de vivir $^{32}$.

En el artículo 130 del Código Penal, el legislador ha previsto como delito la coacción o la obstrucción de las mujeres para iniciar o continuar la cohabitación o la coacción para el divorcio ${ }^{33}$.

El Código Penal castiga no sólo la explotación de mujeres para la prostitución, sino también el tráfico de la prostitución, tanto fuera del territorio de la República de Albania, como dentro de ella ${ }^{34}$

Mientras tanto, con los cambios de 2013, el legislador criminaliza el ejercicio de la violencia sexual mediante el añadido del artículo 107/a del Código Penal, titulado "Violencia sexual". Según este artículo, el ejercicio de la violencia sexual, mediante la realización de actos de naturaleza sexual en el cuerpo de otra persona con los objetos, que constituye un delito y se castiga con tres a siete años ${ }^{35}$.

Partiendo de los resultados de tantos estudios en la sociedad albanesa que describen que las muejeres sufren violencia por parte de sus maridos, ha sido cambiado el artículo 102 del código penal, que castiga la violencia sexual que puede ser ejercitada entre los cónyuges.

El Código Penal tutela a las mujeres víctimas de los abusos sexuales. Por lo tanto, en virtud del artículo 108/a, titulado "El acoso sexual", castiga determinados comportamientos sexuales que violan la dignidad de una persona, por cualquier medio o forma, crea un entorno amenazador, hostil, degradante, humillante $u$ ofensivo ${ }^{36}$.

Con los cambios de 2012, el legislador albanés predijo un delito específico en el párrafo segundo del artículo 130/a del Código Penal, amenaza grave de muerte o lesiones graves a una persona, un cónyuge, pareja, ex cónyuge o ex pareja o familiares cercanos del agresor. Este cambio ha sido sugerido por el aumento de pena, la abolición de la pena de multa y el aumento de la pena de prisión de 1 a 3 años.

${ }^{31}$ La sanción prevista en el párrafo tercero del artículo 130/a del Código Penal en este caso es de hasta cinco años de prisión.

${ }^{32}$ Esta nueva norma no sólo se ha puesto en marcha para la protección de las mujeres, sino que podemos decir que en la realidad albanesa la mayoría de las personas que son perseguidas son mujeres.

${ }^{33}$ Este artículo fue modificado en 2013 y se añade un nuevo apartado que castiga como delito la solicitud hecha por un adulto o un menor de edad para salir del territorio de la República de Albania con el fin de presionarlo para consolidar el matrimonio.

${ }^{34}$ El aumento de la explotación de mujeres y niñas para la prostitución en el país instó al legislador en 2013 a hacer algunos cambios en el artículo 110/a del Código Penal, además de sancionar el tráfico fuera del territorio de la República de Albania y la trata de mujeres en el país. Además, se añadió la pena de prisión a un mínimo de cinco a ocho años.

${ }^{35}$ En el artículo 107/a, el legislador ha previsto el aumento de la pena en los casos en que el delito se realiza en cooperación, en contra de varias personas, más de una vez o en contra de menores de edad; considerando que cuando este acto ha dado como resultado la muerte o el suicidio de la víctima la pena es aún mayor.

${ }^{36}$ Este artículo se añadió con los cambios introducidos en el Código Penal en 2013. 
Es importante señalar aquí que, para prevenir la violencia doméstica, la Ley "De las medidas de prevención a la violencia doméstica" establece salvaguardias en los casos de violencia doméstica. Tales son la orden de protección y la orden de emergencia de la protección ${ }^{37}$. Con respecto a la aplicación de los contenidos de estas medidas, en el párrafo segundo del artículo 321 del Código Penal establece una pena de hasta dos años de cárcel a todas aquellas personas que cometan actos contrarios a la decisión del tribunal en relación con las obligaciones derivadas de órdenes de protección de datos de ella ${ }^{38}$. Mientras tanto, la Ley "De supervisión electrónica de las personas cuya movilidad está limitada", predijo la implementación de la vigilancia electrónica contra personas contra las que se ha redactado, el mandato judicial, una orden de protección o una orden de protección de emergencia ${ }^{39}$. Para garantizar una aplicación eficaz de las órdenes de protección y vigilancia electrónica, el legislador en 2013 añade al artículo 50 del Código Penal dos circunstancias agravantes en las que el acto criminal, mientras la persona esté bajo la orden de protección o bajo vigilancia electrónica, considerado como un delito cometido en circunstancias agravantes ${ }^{40}$.

Como conclusión de este análisis podemos decir que los recientes cambios en el Código Penal se caracterizan por la introducción de importantes sanciones para los casos de violencia doméstica dirigidas no sólo castigar estas conductas problemáticas para la sociedad, sino también prevenirlos.

\section{CONCLUSIONES Y RECOMENDACIONES}

Las mujeres disfrutan de una protección penal y jurídica mejorada en los últimos años. La política criminal se endureció después de los cambios realizados en el Código

\footnotetext{
${ }^{37}$ El artículo 10 de la Ley Nr. 9669, de fecha 18.12.2006, "Sobre las medidas contra la violencia doméstica", según enmendada. ANASTASI, A.: Çështje për një proçes të rregullt ligjor gjatë zbatimit të ligjit "Për masat ndaj dhunës në marrëdhëniet familjare" (Cuestiones para un proceso legal regular durante la aplicación de la ley "Sobre las medidas contra la violencia doméstica"), në Konferencën shkencore ndërkombëtare "Mekanizmat mbrojtës të të drejtave të individëve në kuadër të proçesit të rregullt ligjor" (Conferencia Científica Internacional "Los mecanismos para proteger los derechos de las personas en el proceso de la ley"), Pegi, Tirana, 2012, págs. 9 y ss.

${ }^{38}$ El segundo párrafo del artículo 321 del Código Penal se añadió en 2012. Basado en el análisis judicial de los estudios realizados por organizaciones de la sociedad civil que prestan apoyo a las víctimas de la violencia doméstica, se concluye que el número de juicios por obstruir la ejecución de las decisiones judiciales de personas a las que, por decisión judicial, se le da un orden de protección, se incrementa. Sólo el tribunal de distrito de Tirana, en 2011 sentencíó en una ocasión por el delito previsto en el artículo 321, mientras que en 2012 lo hizo en cuatro. Botim i Qëndrës për Nisma Ligjore dhe Qytetare, Njohja dhe zbatimi $i$ standarteve të barazisë gjinore në proçesin gjyqësor. Raport mbi gjetjet kryesore nga monitorimi i vendimeve të gjykatave të shkallës së parë, të rretheve Tiranë, Durrës, Shkodër e Vlorë: 1 janar 2011-1 qershor 2012, (Publicación del Centro de Iniciativas legales y cívicos: Reconocimiento y aplicación de las normas de igualdad de género en el proceso judicial. Informe sobre las principales conclusiones de la fiscalización de las decisiones de los tribunales de primera, de Tirana, Durres, Shkodra y Vlora: 01.01.2011-01.06.2012), 2013, pág. 54.

${ }^{39}$ Ligji Nr.10494, datë 22.12.2011 "Për mbikqyrjen elektronike të personave, të cilëve u kufizohet lëvizja me vendim gjyqësor" (Ley Nr.10494 fecha 22.12.2011 "Para la vigilancia electrónica de las personas cuyo movimiento fue restringida por una decisión judicial").

${ }^{40}$ Neni 6 i Ligjit Nr.144, datë 02.05.2013, "Për disa shtesa dhe ndryshime në Ligjin Nr.7895, datë 27.01.1995 “Kodi Penal i Republikës së Shqipërisë" i ndryshuar" (El artículo 6 de la Ley Nr.144, de fecha 02.05.2013, "En algunas adiciones y enmiendas a la Ley Nr. 7895, de fecha 01.27.1995" Código de la República de Albania, modificado).
} 
Penal, sobre todo entre 2012 y 2013. Cambios en las políticas penales deben ser evaluados en cuanto al efecto de prevenir la violencia contra las mujeres, así como el aspecto financiero que implica estimar el costo de los servicios sociales para las mujeres, la víctima, la rehabilitación de los presos y sus efectos en el entorno familiar.

Se siente la necesidad de intensificar la lucha contra la violencia doméstica y contra de las mujeres en Albania. Debe construir una buena relación de cooperación entre el Gobierno y la sociedad civil para combatir la violencia contra las mujeres. Con el fin de reducir la incidencia de la violencia contra las mujeres en Albania, es necesario crear una visión compartida que nos llevará a la acción conjunta. No solo para prevenir la violencia, sino también para ayudar a las víctimas, es necesario que abogados, psicólogos, médicos, policías y trabajadores sociales trabajen juntos.

Teniendo en cuenta la necesidad de prevenir y reducir el fenómeno de la violencia contra la mujer, a continuación trataremos de hacer algunas recomendaciones que se cetrarán en la actividad con lan comunidad, con la Policia del Estado y la colaboración entre las diferentes instituciones.

Es importante aumentar la conciencia de la comunidad sobre las leyes sobre la violencia contra la mujer, las autoridades competentes y su papel sancionados por la ley, los procedimientos en los casos de denuncias de casos de violencia doméstica, las medidas de protección, servicios de apoyo para las víctimas y los perpetradores. Es necesario promover los derechos humanos, con especial atención a los derechos de los niños, las mujeres y las minorías; tratar el fenómeno y las diversas formas de violencia doméstica; incrementar la confianza entre la población para aumentar el nivel de denunciar el delito. Estas actividades tienen que ser llevadas a cabo por la policía y otras autoridades pertinentes, haciendo visitas regulares a las escuelas, seminarios con los estudiantes, la preparación y la distribución de folletos informativos y actividades de sensibilización en otros medios, la promoción de experiencias positivas y de gestión con éxito en los casos de violencia en la familia. Tales actividades deben considerarse una prioridad en áreas específicas y comunidades con muy bajos niveles de conciencia y el reporte del fenómeno de la violencia en la familia, como las zonas rurales y del norte, o áreas en las que se establecen las minorías nacionales.

Es importante mejorar la imagen pública de la policía mediante el fortalecimiento de las relaciones con la comunidad, dando importancia al rol positivo que este órgano desempeña: por ejemplo mejorar los servicios que ofrece este órgano a la comunidad en general y en particular modo en los casos de violencia contra mujer baándose sobre la profesionalidad, la independencia y el repeto de la ética profesional. Es necesario hacer entender a la población, a través de la ayuda de los medios de comunicación, que la policía del Estado ejerce un rol muy importante. De esta manera se le dará forma precisa y completa al papel de la policía en respuesta a la violencia doméstica contra las mujeres, garantizando la difusión de información al público adecuado. Teniendo en cuenta que los medios de comunicación son muy seguidos por parte de la población y la televisión representa la fuente principal de información, es necesario hacer pactos de colaboración con las televisiones locales y nacionales para dar más relevancia a la Policía del Estado y cuestiones de violencia doméstica. Establecer una conexión (link) en el sitio web de la Policía del Estado para proporcionar información concreta, asesoramiento detallado y práctico sobre la violencia contra la mujer, el papel actual de la policía y otra información necesaria sobre los servicios disponibles, direccionados 
sobre todo a los jóvenes que son aquellos que en la mayor parte de los casos utilizan más internert, medio que representa una manera óptima de transmitir información. La organización de las actividades dentro de las comisarías de policía con la presencia de la población y representantes de instituciones estatales y de asociaciones que trabajan en este sector con el objetivo de presentar el rol, las novedades y logros de la policía. Realización de una serie de medidas para mejorar la labor de los órganos de la Policía del Estado, como el añadido de las empleadas, la revisión de la estructura responsable de la violencia contra las mujeres por parte de la zonificación dinámica, para continuar la formación y el perfeccionamiento de todos los agentes de policía que frente a la violencia contra las mujeres, especialmente las que tienen contacto directo con la víctima, a considerar también la revisión de los recursos humanos, la racionalización de las estaciones locales internos para crear más espacio para las entrevistas individuales de las víctimas y adecuado para las mujeres, mejorar la infraestructura, el aumento de los recursos financieros y logísticos, y el uso de la última tecnología.

Es importante organizar sistemáticamente la formación conjunta con los empleados de las diversas instituciones que se ocupan de la violencia contra las mujeres, que tienen por objeto los cambios legislativos, nuevas estructuras, que también traerán una mayor conciencia del papel de cada uno, es decir, puntos de vista y las preocupaciones relacionadas, así como el fortalecimiento de las relaciones interinstitucionales.

Todos los actores responsables en la violencia contra la mujer deberían de realizar los deberes que propone la ley: construir centros de servicios para las víctimas o asegurar su funcionamiento en los casos en que esto ya exista. Construír el mecanismo del sistema de reacción o denuncia de la violencia contra la mujer en todos los ayuntamientos del Estado, asgurando su funcionamiento en los casos es los que ya exista. Reorganizar los recursos humanos y otras fuentes para responder al rol que marca la ley. Reforzar más la colaboración entre instituciones: reuniones periódicas, información continua, unificar el sistema actual de unificación de dtos de diferentes instituciones para los casos de violencia contra la mujer.

\section{BIBLIOGRAFÍA}

ANASTASI, A.: Çështje për një proçes të rregullt ligjor gjatë zbatimit të ligjit "Për masat ndaj dhunës në marrëdhëniet familjare" (Cuestiones para un proceso legal regular durante la aplicación de la ley "Sobre las medidas contra la violencia doméstica"), në Konferencën shkencore ndërkombëtare "Mekanizmat mbrojtës të të drejtave të individëve në kuadër të proçesit të rregullt ligjor" (Conferencia Científica Internacional "Los mecanismos para proteger los derechos de las personas en el proceso de la ley"), Pegi, Tirana, 2012. 
BABAN, A.: Dhuna ndaj grave në familje në Shqipëri (La violencia contra las mujeres en Albania), Unicef, Tirana.

ÇOBA, L.: Kanuni shqiptar sipas nje doreshkrimi te vitit 1868 (Albanés Kanun según un manuscrito de 1868), ne Revistën Drejtësia Popullore (Diario de la Justicia Nacional), n. 5, Tirana, Fakulteti Juridik, Universiteti i Tiranës (Facultad de Derecho, Universidad de Tirana), 1963.

DHULI, B.: Të drejtat e gruas-mosrespektimi praktik dhe pasojat e tij në ndërtimin e së ardhmes (Derechos de la Mujer desprecio práctica y sus consecuencias en la construcción del futuro), en Revista Studimore-Shkencore, Buletini Shkencor Nr.1 (La revista de Investigación Científica, Nr.1 Boletín Científico), Qëndra kërkimore zhvillimore-Peja, Peja, 2014.

HAARR, R. N.: Dhuna në familje në Shqipëri: Vrojtim kombëtar me bazë popullatën (La violencia doméstica en Albania: la población nacional a base de observación), United Nations Development Program-UNDP, Tirana, 2013.

HAARR, R. N., DHAMO, M.: Dhuna në familje në Shqipëri: Sondazh kombëtar me bazë popullatën (La violencia doméstica en Albania: encuesta nacional de base poblacional), INSTAT, Tirana, 2009.

HAXHIYMERI, E., KULLURI, E., POST, D.: Standardet e shërbimeve të përkujdesjes shoqërore për viktimat $e$ dhunës në familje, në qendrat rezidenciale, publike dhe jopublike (Normas de servicios de asistencia social para las víctimas de la violencia doméstica, en residencial, público y privado), UNDP- Programi i Kombeve të Bashkuara për Zhvillimin (Programa de Naciones Unidas para el Desarrollo), Tirana, 2013.

HYSI, V.: Politika penale për veprat penale kundër grave dhe fëmijëve (Política criminal en relación a los delitos contra las mujeres y los niños), në Revistën "Studime Juridike" Nr.2, Fakulteti i Drejtësisë, Universiteti i Tiranës (en Revista "Estudios Jurídicos" Nr.2, Facultad de Derecho, Universidad de Tirana), Europrint, Vlora, 2014.

HYSI, V.: Politika penale ndaj grupeve të veçanta në shoqëri (La política criminal hacia determinados grupos de la sociedad), ne LATIFI, V., ELEZI, I., HYSI, V.: Politika e luftimit të kriminalitetit (La política de lucha contra la delincuencia), Botim i Institutit Evropian për Studime Juridike dhe Administrim Publik, Koha Print, Prishtina, 2012.

KOSTA, A.: Dhuna në familje dhe ndaj grave (La violencia doméstica y hacia las mujeres), Tirana, 2007.

KURTI, S.: Analiza e shkaqeve të dhunës në familje dhe reagimi i jurisprudencës përballë rasteve të tilla (Análisis de las causas de la violencia doméstica y la jurisprudencia reacción opuestos tales casos), në Konferenën Shkencore Ndërkombëtare: Shteti, shoqëria, e drejta - shqiptarët 25 vjet nga ndryshimi i sistemeve 
(Internacional Científico Conferencia: Estado, la sociedad, a la derecha - albaneses de 25 años de sistemas de cambio), Universidad "Alexander Moisiu", Durres, mayo 2015. KURTI, S.: Studimi i kriminalitetit nga këndvështrimi i viktimave (El estudio de la delincuencia desde la perspectiva de las víctimas), në bashkëpunim me studentët e lëndës Kriminologji dhe Penologji, Departamenti i së Drejtës Penale, Fakulteti i Drejtësisë, Universiteti i Tiranës, qershor 2012 (en colaboración con los estudiantes de la asignatura de Criminología, del Departamento de Derecho Penal de la Facultad de Derecho de la Universidad de Tirana, junio 2012).

KURTI, S.: Studim mbi dhunën në familje (La investigación sobre la violencia doméstica), në bashkëpunim me studentët e lëndës Kriminologji dhe Penologji, Departamenti i së Drejtës Penale, Fakulteti i Drejtësisë, Universiteti i Tiranës, maj 2014 (en colaboración con los estudiantes de la asignatura de Criminología y Criminología, del Departamento de Derecho Penal de la Facultad de Derecho de la Universidad de Tirana, mayo 2014).

LUARASI, I., FUGA, A., PILIKA, A., GADESHI, E.: Studim për viktimat e krimit të dhunës në familje dhe sulmeve seksuale (Estudio sobre las víctimas de delitos de violencia doméstica y asalto sexual), Edlora, Tirana, 2013.

OMARI, L.: E drejta zakonore dhe e drejta zyrtare ne Shqiperi (El derecho consuetudinario y el derecho oficial en Albania), en Revistën Drejtësia Popullore (Diario de la Justicia Nacional), n. 3, Tirana, Fakulteti Juridik, Universiteti i Tiranës (Facultad de Derecho, Universidad de Tirana), 1990.

PEJO, E.: Të drejtat e grave në Evropën e zgjeruar ndërmjet “kulturave të barazisë” dhe sfidave strategjike për të ardhmen (Derechos de las mujeres en la Europa ampliada entre la "cultura de la igualdad" y desafíos estratégicos para el futuro), në Konferencën Shkencore Ndërkombëtare: Mekanizmat e mbrojtjes së të drejtave të individëve në kuadër të proçesit të rregullt ligjor (en la Conferencia Científica Internacional: mecanismos de protección de los derechos individuales en el marco del debido proceso), Pegi, Tirana, 2012.

SHEHU, E., GRAMO, A.: Dhuna me bazë gjinore: Manual për punonjësit $e$ shëndetësisë (Violencia de género: Un Manual para trabajadores de la salud), Tirana, 2008.

XHAFERI, A.: Shkaqe dhe faktorë që nxisin dhunën ndaj gruas (Causas y factores que promueven la violencia contra las mujeres), në Konferencën shkencore ndërkombëtare: Demokracia në Evropën Juglindore (en Conferencia Científica Internacional: La democracia en Europa del Sud-Este), Vëllimi 1 (Volumen 1), Tetova, 2014.

Botim i OSCE, Analiza e sistemit të drejtësisë penale në Shqipëri: Raport i programit për zhvillimin e një gjykimi të drejtë (Publicación de la OSCE, Análisis del sistema de justicia penal en Albania: Informe del programa para el desarrollo de un juicio justo), OSCE, Tirana, 2006.

Studim i Qëndrës së Aleancës Gjinore për Zhvillim: Ministria e Punës, Çështjeve Sociale dhe Shanseve të Barabarta (Estudio realizado por Centro de Investigación de la Alianza de Género para el Desarrollo: Ministerio de Trabajo, Asuntos Sociales e 
Igualdad de Oportunidades), Dhuna në familje: Paraqitje e situatës aktuale (Violencia Doméstica: Resumen de la situación actual), Tirana 2006.

Studim i Qëndrës së Aleancës Gjinore për Zhvillim, Dhuna me bazë gjinore si fenomen shqiptar: Kronologjia e pabarazisë gjinore në Shqipëri-vështrim historik, (Estudio de Centro de la Alianza de Género para el Desarrollo, La violencia de género como fenómeno albanés: Cronología de la desigualdad de género en Albania y reseña histórica), Tirana, 2008.

Estudio realizado por United Nations Development Program-UNDP, Dhuna në familje: Përgjegjësitë që ka Policia e Shtetit për parandalimin dhe reduktimin e saj (Violencia doméstica: Responsabilidades que la Policía del Estado para prevenir y reducir), Tirana, 2008.

Botim i Ministrisë së Shëndetësisë (Publicación del Ministerio de Salud), Një qasje praktike ndaj dhunës me bazë gjinore: Udhërrëfyes për punonjësit e shëndetësisë (Un enfoque práctico de la violencia de género: una guía para los trabajadores de la salud), Ribotim, QKSS - Qendra Kombëtare për Studime Sociale, Tirana, 2011.

Estudio de la Organización para la Seguridad y la Cooperación en Europa-OSCE, Manual: Si të kërkojmë mbrojtje nga dhuna në familje (Manual: Cómo buscar la protección contra la violencia doméstica), Tirana, 2013.

Botim i Qëndrës për Nisma Ligjore dhe Qytetare, Njohja dhe zbatimi i standarteve të barazisë gjinore në proçesin gjyqësor. Raport mbi gjetjet kryesore nga monitorimi i vendimeve të gjykatave të shkallës së parë, të rretheve Tiranë, Durrës, Shkodër e Vlorë: 1 janar 2011-1 qershor 2012, (Publicación del Centro de Iniciativas legales y cívicos: Reconocimiento y aplicación de las normas de igualdad de género en el proceso judicial. Informe sobre las principales conclusiones de la fiscalización de las decisiones de los tribunales de primera, de Tirana, Durres, Shkodra y Vlora: 01.01.201101.06.2012), 2013. 